\title{
Data bases: past, present and future
}

\author{
Donald D. Wagman* \\ 7104 Wilson Lane, Bethesda, MD 20817, USA
}

\begin{abstract}
This historic account reviews briefly the compilation and publication of data in 'thermochemistry and free energy of chemical reactions' starting with the works of the 19th century pioneers, Julius Thomsen and Marcellin Berthelot. The role played by the leading 20th century data enthusiasts, such as Rossini, Lewis \& Randall, Kharasch, Bichowsky, Latimer, and others is documented. Computer technology and networking has resulted in many changes in modern day databases, not only in the methods of dissemination but also in their capabilities, in that many such bases now carry within themselves the methods of estimation of unknown properties and the utilization of such data for calculation of various thermodynamic equilibria as a function of temperature, pressure, and composition.
\end{abstract}

When I was asked to give this talk to the Conference I protested that I had not been actively involved in work on thermodynamic data evaluation for several years. However my 40 years at the U. S. National Bureau of Standards had been spent principally in the preparation of comprehensive data bases for thermodynamics. During those years I had occasion to examine many of the older bases. Some of them are now out of print but they played a significant role in the growth of chemical thermodynamic research and the application of the data to the design and development of industrial processes. The relatively recent growth in computer technology and computer networking has resulted in many changes in modern day data bases, not only in the methods of dissemination but also in their capabilities, in that many such bases now carry within themselves the methods of estimation of unknown properties and the utilization of such data for calculation of various thermodynamic equilibria as a function of temperature, pressure, and composition. I thought that it might be of interest to look back on the history and development of these bases, from the early bases that represented the work and interest of one scientist to the present day bases that are the output of groups of scientists working with institutional support and utilizing the latest in mathematical, computing and publishing techniques. I shall confine myself specifically to those banks that dealt with the data of thermochemistry and free energy of chemical reactions.

But before I go into this early history I would like to say a few words about a man who played a very important role in this field. Frederick Rossini died last October at the age of 91 . Many of you may know Dr. Rossini as one of the small group of scientists who recognized the need for international cooperation and standardization in the collection and evaluation of scientific data and formed a working group in the International Council of Scientific Unions that led to the creation of CODATA. But long before this Rossini had been actively engaged in sponsoring and pushing for the preparation of reliable data bases for thermochemistry and thermodynamics.

\footnotetext{
Former Chief, Chemical Thermodynamics Data Center, National Bureau of Standards, Washington, D.C.
} 
Rossini came to the Bureau of Standards in 1928 to a newly-created Physico-Chemical Research Section. During his first few years there he made measurements on the heats of formation of water and hydrogen chloride by direct combination of the elements that are classical examples of precision flame calorimetry. In 1936 he was made chief of a new Section entitled Thermochemistry and the Constitution of Petroleum, which position he held until he left the Bureau in 1950. The title of this new Section directly indicates the focus of his interests and efforts for the rest of his scientific career. He and F. R. Bichowsky had collaborated in the preparation of a book "Thermochemistry of the Chemical Substances", which was published in 1936. As a result of the success of that publication the Bureau established an official research project designed to prepare an extensive revision of that work, the project being under Rossini's direct supervision. When I came to work for Rossini in 1940 it was as the first full-time chemist assigned to that project.

In 1942 the Bureau established API Research Project 44, supported by the American Petroleum Institute and under Rossini's direction, to prepare tables of best values of the physical and thermodynamic properties of hydrocarbons. Before Rossini left the Bureau in 1950 the NBS had published Circular 461, "Selected Values of Properties of Hydrocarbons" and Circular 500 "Selected Values of Chemical Thermodynamic Properties", the direct results of these two projects. I'll have more to say about these two publications later.

In 1950 Rossini went to the Carnegie Institute of Technology (now the Carnegie-Mellon Institute) as Silliman Professor of Chemistry and Director of their Chemical-Petroleum Research Laboratory, in which Laboratory the work of the API RP44 on the evaluation and dissemination of data on the properties of hydrocarbons continued. In 1960 he left Carnegie to go to the University of Notre Dame as Dean of the College of Sciences and Associate Dean of the Graduate School. But as always he retained his intense interest and support for programs engaged in the critical evaluation of scientific data and it was this interest that spurred the International Council of Scientific Unions to establish CODATA as a specific organizational unit devoted to promoting international cooperative efforts in this area.

Rossini retired as Emeritus Professor from Notre Dame in 1971 to go to Rice University in Texas, which he left in 1978, retiring to live in Florida, although he still maintained an active interest in the growth and development of CODATA.

During his lifetime Rossini was the recipient of many awards and recognitions, including the Hillebrand Award of the Chemical Society of Washington in 1934, The Priestley Medal of the American Chemical Society in 1971, and the National Medal of Science (USA) in 1977. He was the author or coauthor of 265 scientific publications, including 11 books. His article in 1939 with W.

E. Deming entitled "The assignment of uncertainties to data of chemistry and physics, with specific recommendations for thermochemistry" guided thermochemical practice for many years.

Data banks provide useful compilations of numerical or other factual data for science and technology. To be useful such compilations must be readily available to users. For that reason I plan to concentrate in this report principally on printed published material, and will discuss only briefly the newer developments that make extensive use of computers and computer-readable files. 
The earliest compilation that I encountered is one that has continued to amaze me over the years. It is the four-volume set "Thermochemische Untersuchungen" by the Danish thermochemist Julius Thomsen. The four volumes were published during the years $1882-1887$ and present in compact form the results of his own thermochemical investigations. This work actually started in 1853. In that year (only a few years following the work of Mayer, Joule, and Helmholtz that led to the establishment of the First Law of Thermodynamics) Thomsen published in Poggendorfs Annalen der Chemie a paper in which he outlined his plan for a comprehensive study of the energetics of chemical reactions, his system for presentation of the data, and described the notation to be employed. He continued this work for over 30 years, the final results appearing in the fourvolume set mentioned. In each volume are given not only summary tables of the heats of chemical reactions, heats of solution, heats of combustion of organic compounds, and heat capacities, all obtained in his laboratory, but also details of the individual experiments, such as the amounts of substance reacted, temperature changes observed, energy equivalents of the calorimeter system, and a discussion of each system studied. The volumes cover 2450 individual measurements on reactions of approximately 50 metallic and non-metallic elements with oxygen, halogens, sulfuric and nitric acids, and more than 400 measurements on organic compounds. A one-volume version of this work, omitting all experimental details and including some revised values for calcium compounds, was published in Danish in 1905. In the Introduction to this abbreviated work Thomsen wrote:

"It is my desire to provide in the Danish language a permanent record (or memorial) of the large amount of experimental work done at one of Denmark's principal scientific Institutes, the value of which will surely continue to be appreciated as time goes on."

Interestingly this permanent record in the Danish language exists in the library of the U.S. National Bureau of Standards only as German and English translations.

The next major compilation was again the work of one man, the well-known French chemist Marcellin Berthelot. Berthelot had worked for many years in synthetic organic chemistry but in 1869 he started a major program on the use of the calorimetric combustion bomb to determine the heats of formation of organic substances. He attracted many other investigators to his laboratory, which became the leading institution for these measurements. The output of the laboratory was tremendous, but it was not always of the highest quality. However he was principally concerned with generalizations rather than precision. He also had a great disregard for the results of others. This is expressed specifically in his two-volume work "Thermochimie. Donnees et Lois Numerique," published in 1897. In this work he presented his selected values for the heats of formation of a large number of inorganic and organic compounds. The inorganic substances covered compounds of 30 metallic elements and ammonia with halides, sulfides, sulfates, cyanides, etc. The organic compounds included hydrocarbons, alcohols, phenols, aldehydes, acids, esters, and nitrogen-containing compounds. In publishing this work, Berthelot decided to select what he believed to be the best value for a given substance, and he also included the measurement for the experimental reaction from which the value was derived. In the 
Introduction Berthelot discussed his philosophy for choosing the value:

"One procedure consists of giving all the results obtained by experimenters, sometimes numbering 8 or 10 for a given reaction (such as the reaction of hydrogen with oxygen), then take the mean. This is very unsatisfactory because the values obtained successively by different authors during the past century are of very unequal quality. Regardless of the merit of the researchers, this inequality is inevitable, by reason of the continued improvement in methodology and basic knowledge.

The other procedure is to choose from among only the most recent measurements made by the more authoritative experimentalists. I would add that it is preferable to choose from among these the results obtained by the same general method in order to form a more consistent set of values. For this reason I have naturally selected determinations made by me or my students under my direction. As Descartes said, it is difficult to arrive at perfect results by working only with the results of others."

Of the quantities not measured in his laboratory Berthelot selected as best the values reported by Thomsen in the first three volumes of his Thermochemical Researches (on inorganic compounds). In general where he and Thomsen had studied the same system, he found their results in excellent agreement. However for organic compounds, he accepted practically none of Thomsen's work. He maintained that bomb combustion calorimetry was much to be preferred over Thomsen's "universal burner", yielding a more complete reaction and better defined reaction products.

The next data collection I would like to mention was not intended for that purpose, but rather as illustrative of the methods available for the analysis of chemical thermodynamic data. This collection appeared in Lewis and Randall's famous textbook "Thermodynamics and the Free Energy of Chemical Substances", published in 1923. The last section of the book is entitled "Introduction to Systematic Free Energy Calculations", and discusses the evaluation of Gibbs free energy changes as a function of temperature for a number of important chemical reactions and systems. The authors analyze the various enthalpy, entropy, and equilibrium measurements, and the calculations used to obtain the final selected value. Data for approximately 130 substances are then presented in the form of $\mathrm{G}-\mathrm{T}$ equations. While the number of substances was not large this work was the first to present in detail all of the calculations and arguments leading up to the value selected, thus allowing the reader to make his own assessment of the value if he so desires.

The first modern attempt to bring together all published data on the enthalpies of chemical reactions and to prepare an internally consistent table of selected values of heats of formation of chemical substances appeared in 1929 as a section in Volume $\mathrm{V}$ of the International Critical Tables. The preparation of this monumental set of critically selected numerical data for physics, chemistry and technology was undertaken by the U. S. National Research Council in 1919 as a result of a recommendation by the International Union of Pure and Applied Chemistry, and became the first major international cooperative effort in this field. The section on the heats of combustion of about 830 organic compounds, prepared by M. S. Kharasch, contained only the selected value for each substance and the literature source for the measurement. Additional details, including a simple computational scheme for estimating heats of combustion of various classes of compounds were given in a separate article published in 1929 in the Bureau of 
Standards Journal of Research. However neither work contained any information about the original work other than the method of measurement and the result.

The section of the I. C. T. on the thermochemistry of inorganic compounds (and C-1 and C2 organic compounds) was prepared by F. R. Bichowsky and contained data on approximately 3700 substances obtained from over 1100 references. Because of the need for self-consistency in tables of heats of formation, all original data were carefully corrected where possible to uniform energy and temperature scales and to uniform atomic weights. The evaluation process was a sequential one in which the tables were built up compound by compound, using as auxiliary data only values already accepted for the tables. (This approach to obtain self-consistency has been followed in all future comprehensive evaluations. Only in recent years has the development of computers made a large-scale simultaneous solution possible.) The actual data presented in the tables are skeletal in that for each substance is given the enthalpy of formation, a symbolic description of the method or reaction from which the value was obtained, and an appropriate reference citation. Values for pure substances and for aqueous solutions are given. Again as in the past this tremendous compilation work was essentially a one-man effort made possible by the fact that Bichowsky had been personally compiling brief summaries of published thermochemical data on $3 \times 5$ cards for many years.

Then in 1936 Bichowsky and Rossini published "Thermochemistry of the Chemical Substances". This work took the material from the section of the Critical Tables, added some additional, newer material, and reevaluated it into a new set of self-consistent best values for the enthalpies of formation of about 3700 chemical species. Accompanying the tables were a bibliography and a section of text in which was described the derivation of the value given. This work was tremendously successful as a definitive source for enthalpy of formation data as well as such auxiliary data as enthalpies of transition and solution.

It was during this same period that $\mathrm{K} \mathrm{K}$. Kelley of the U. S. Bureau of Mines started publication of a series of Bulletins entitled "Contributions to the Data of Theoretical Metallurgy". The first Bulletin, which appeared in 1932, was a collected set of entropies and heat capacities for inorganic substances. Additional Bulletins appeared at intervals in subsequent years until 1961. These Bulletins recognized that chemical technology required knowledge not only of heats of formation but also entropy and heat capacity data to make possible the calculation of the behavior of systems at high temperature. Some of the Bulletins dealt with the thermodynamic properties of families of inorganic substances, such as sulphur compounds, nitrogen compounds, and carbonates. In these the available data were carefully evaluated and the results expressed in the form of analytical equations as a function of temperature. Other Bulletins dealt explicitly with entropies at $298 \mathrm{~K}$ and high temperature heat content data.

In 1938 Latimer published "The Oxidation States of the Elements and their Potentials in Aqueous Solutions", a thorough review of data on inorganic aqueous systems. It was thoroughly revised and updated in 1952.

In 1940, as previously mentioned, the U. S. Bureau of Standards started a program to prepare an extension and revision of the Bichowsky and Rossini work. However World War II 
intervened and work on that project was suspended. The increased interest in petroleum and petroleum refining and the Bureau's ongoing work on the hydrocarbon Standard Sample program led to the publication in 1947 of NBS Circular 461. This volume contained values for a number of physical and thermodynamic properties of various classes of hydrocarbons (paraffins, cycloparaffins, olefins, alkylbenzenes, and acetylenes). Values for the thermal functions were given from $0-1500 \mathrm{~K}$. This work was continued by Rossini at the Carnegie Institute of Technology and resulted in the publication in 1953 of "Selected Values of Physical and Thermodynamic Properties of Hydrocarbons and Related Compounds"' by Rossini, Pitzer, et al. This book included data for additional classes of hydrocarbons and sulphur-containing organic compounds. This compilation effort continues today as the output, in loose-leaf form, from the Thermodynamics Research Center at Texas A and M. University, with K. N. Marsh as Director of the Project.

In 1947 the Bureau resumed work on the revision of Bichowsky and Rossini with the distribution on a quarterly basis of a set of loose-leaf sheets entitled "Selected Values of Chemical Thermodynamic Properties". These sheets were issued in three Series. Series I contained selected values of enthalpy and Gibbs energy of formation, entropy, and heat capacity for chemical substances at $298 \mathrm{~K}$; Series II contained selected values for the temperature and enthalpy of phase transitions; Series III tabulated values of the thermodynamic functions for individual substances to $1500 \mathrm{~K}$. The work on Series I and II was completed in June 1950, and NBS Circular 500, containing both Series I and II tables and references, was published in 1952. Data were presented for approximately 7000 substances.

Just about this time (1950) there was published a volume entitled "Chemistry and Metallurgy of Miscellaneous Materials", edited by L. L. Quill. This was part of the National Nuclear Energy Series, and summarized work that had been done as part of the U. S. Nuclear energy program. In it were reviews by Brewer of the thermodynamic properties of the elements and inorganic halides. Many estimates were provided, and an extensive review of the literature was included.

In 1956 there appeared the first complete compilation of the thermodynamic properties of the elements at closely spaced temperature intervals from 298 to $3000 \mathrm{~K}$. This was a Monograph in the Advances in Chemistry Series by Stull and Sinke entitled, aptly enough, "Thermodynamic Properties of the Elements". The tables gave the thermal functions for 92 elements in the solid, liquid, and gaseous phases. Sources for the values were given, with many being based on the earlier reviews by Kelley.

Some of the above material was reanalyzed in the work entitled "Selected Values of Thermodynamic Properties of Metals and Alloys", by Hultgren, Orr, Anderson, and Kelley, published in 1963, and then further extended and completely revised by Hultgren and others in 1973. This revision was published as two separate parts; the first volume contained complete reviews of the low and high temperature heat capacity measurements, calorimetric heats of fusion and vaporization, and vapor pressure data for 89 elements, as well as a complete bibliography for each element. 
In 1969 Stull, Westrum, and Sinke published "Chemical Thermodynamics of Organic Compounds". They reviewed the literature up to 1966 and presented values for enthalpy and Gibbs energy of formation and thermal functions from $298-1000 \mathrm{~K}$ for 740 organic substances and data at $298 \mathrm{~K}$ for approximately 3700 additional substances. It included a discussion of the sources of the data and an evaluation of the reliability of the results. A revised edition of this work was published in 1987.

A complete updating and expansion of the work by Kharasch on heats of combustion of organic compounds was published in 1970 by Cox and Pilcher. This work, entitled "Thermochemistry of Organic and Organometallic Compounds", reviewed the literature from 1930 to 1968 and provided a critical assessment of all the pertinent data. It gave the method of measurement, the number of individual experiments, the measured enthalpy of reaction (corrected to standard states when possible) as well as the calculated enthalpy of formation. For many systems several sets of data are given, from which the authors have selected the best value. Approximately 2000 substances are covered in these tables. Then in 1986 Pedley, Naylor, and Kirby published "Thermochemical Data of Organic Compounds". This contained data on enthalpies of formation at $298 \mathrm{~K}$ for about 3000 substances. Most of the material prior to 1968 is taken directly from the work of Cox and Pilcher; newer data to 1983 are also included. A scheme for the estimation of the enthalpy of formation of an unknown compound based on contributions from structural components is also given.

In 1959 the U. S. Department of Defense initiated a program to critically evaluate and compile values for the thermodynamic properties of substances important in studies of combustion of a number of compounds of the lighter elements then being considered for high energy fuels. These tables, called the JANAF Tables because of joint Army-Navy-Air Force support, were prepared under the supervision of D. R. Stull at the Dow Chemical Corporation. The first tables appeared in 1960 in the form of loose-leaf sheets and the first assembled volume was published in 1965. The original purpose of this program was to provide a self-consistent set of reliable thermodynamic data for use by the aerospace industry to make theoretical engine performance calculations. Thus input data would not be a cause for disagreement between various calculation programs. Values were given for enthalpy and Gibbs energy of formation and thermal functions at 100 degree intervals from 298 to as high as $6000 \mathrm{~K}$ Also included for each substance was a brief analysis of all data used in the individual evaluations. While the first edition was limited to simple compounds of the so-called light elements, the tables were so well received that the later editions were significantly increased in scope and were incorporated into the U.S. National Standard Reference Data System. The second edition of the tables, edited by Stull and Prophet, was published in 1975 as NSRDS-NBS 37, and a third edition, edited by M. R. Chase et al. appeared in 1985 as a Supplemental Publication of the Journal of Physical and Chemical Reference Data. The first edition of the tables contained data for approximately 625 different substances covering 22 elements, the third edition covered 1800 substances and 47 elements.

At almost the same time as the JANAF Tables were being prepared a very similar program was underway in the U.S.S.R., and for essentially the same reasons. "Thermodynamic Properties 
of the Components of Combustion Products" by L. V. Gurvich et al. was published by the Academy of Sciences, U.S.S.R. in 1956. This set of 3 volumes covered the thermodynamic-properties from 293 - $6000 \mathrm{~K}$ for 234 substances composed of 21 elements. In 1962 this work was superseded by the publication by Gurvich and others of a two-volume "Thermodynamic Properties of Individual Substances", containing calculations of the properties of 335 substances of 31 elements. (The list of elements was almost identical with that covered by the first JANAF tables; to my knowledge neither group knew of the work of the other). The third edition of this work consists at the present time of 4 volumes and covers the thermodynamic properties of 1070 compounds of 47 elements. (A fifth volume is in preparation). The material for each substance is considered in great detail and many tables of auxiliary data are included as well as complete bibliographies. The four volumes have appeared from 1978 - 1981. Each volume consists of two parts, one contains the tables, the other contains the textual material related to the tables. Each table, in addition to the numerical values, contains an analytical expression for the Gibbs energy function - temperature relation and an indication of the general reliability of the values. An English translation of this work is being prepared; Volume I of the translation appeared in 1990.

Another coincidence in the history of these data banks occurred in 1965. In that year the National Bureau of Standards published the first part of a totally new revision of the data in Circular 500. This was the beginning of a complete reexamination of the data for all inorganic compounds, but limited itself to giving values only at $298 \mathrm{~K}$. Following the order of presentation used in Circular 500 and using a manual sequential treatment of the data, this first volume, designated NBS Technical Note 270-1, presented values for compounds of the first 23 elements in the Standard Order of Arrangement. Subsequent parts of the tables appeared at intervals, with the final eighth part being published in 1981. These tables were based on the then-accepted standard state for gases as the ideal gas at 1 atmosphere. They were corrected to 1 bar $(0.1 \mathrm{MPa})$ and published in 1982 as a Supplement to Volume 11 of the Journal of Physical and Chemical Reference Data. The tables cover the same properties as the Series I portion of Circular 500, but no references are given. The documentation is being assembled in the form of a catalog of all the reaction data used in the evaluation. The catalog is designed for use in a computer-assisted network solution and provides information on the reaction measured, the corrections applied, and the final corrected value for the reaction. It is intended to provide the basic set of data for any future revision of these tables.

At the same time (1965) the Institute for High Temperatures in Moscow published Volume I of a set of tables called "Thermal Constants of Substances". This work by Medvedev et al. was the result of a complete reevaluation of all the data on compounds of the first 13 elements in the Standard Order of Arrangement. Additional volumes covering other elements appeared at intervals with the final tenth volume published in 1981 . These tables cover not only enthalpy and Gibbs energy of formation, entropy, heat capacity and enthalpy content at $298 \mathrm{~K}$ but also values for temperatures and enthalpies of transition. In addition to the tables references to the sources from which the values were derived are given. Thus during the years 1965 - 1981 two separate groups were engaged in very similar activities in data evaluation. Although the two programs 
started out independently, neither knowing of the other, contact between the two working groups was established in 1967. It was decided early on that the two programs, already well under way, would continue their work as originally planned but that methods for future cooperative work would be explored. This involved exchanges of microfilms and other bibliographic materials, computer programs for analyzing and evaluating reaction data, and exchanges of personnel for short periods of time.

Recognizing a need for internationally accepted thermodynamic data and that a coordinated large-scale effort would be required to obtain such data CODATA in 1968 established a Task Group on Key Values for Thermodynamics. This group resolved to concern itself only with substances that are ubiquitous in any systematic evaluation of thermochemical and thermodynamic properties of chemical substances, and the elements of which these compounds are composed. The properties to be evaluated and selected included the enthalpy of formation, entropy, and enthalpy content, all at $298 \mathrm{~K}$. The Task Group was to assemble all the pertinent literature, assess the data for reliability, and publish recommended values based on their assessment. The original members of the Task Group comprised scientists from the United States, the Soviet Union, England, and Sweden, with S. Sunner of Sweden as chairman; he was later succeeded by J. Cox of England. The final report of the Task Group, edited by Cox, Wagman, and Medvedev, was published in 1989 as "CODATA Key Values for Thermodynamics". Along with the selected values for 151 key chemical species is included a catalog of 513 reactions used to evaluate the enthalpies of formation and the entropies of the aqueous ions. Also included are tables of the thermal functions from $0 \mathrm{~K}$ to high temperatures for 107 substances used in the evaluation process, and extensive text material on each evaluation. All data in the tables are based on standard states at 1 atmosphere pressure.

Following the publication of the Key Values report CODATA established a Task Group on Chemical Thermodynamic Tables, with H. J. White as chairman. This group has published a volume entitled "CODATA Thermodynamic Tables: Selections for Some Compounds of Calcium and Related Mixtures: A Prototype Set of Tables", edited by Garvin, Parker, and White; a similar volume on iron is in progress currently.

Two other recent works that should be mentioned here are the compilation by Barin and Knacke entitled "Thermochemical Properties of Inorganic Substances", published in 1973, and an extended revision by Barin entitled "Thermochemical Data of Pure Substances" published in 1989. The latter work contains 2370 tables of values for enthalpy and Gibbs energy of formation, entropy, heat capacity, and Gibbs energy function from 298 to $2000 \mathrm{~K}$ (some gases go to $5000 \mathrm{~K}$ ). Both of these works rely heavily on earlier compilations such as the JANAF Tables, NBS Technical Note 270, and Kubaschewski, Evans, and Alcock for many of their basic values at $298 \mathrm{~K}$.

In addition to these general data banks, there are many that deal with limited classes of compounds. Two significant such compilations are Mills' "Thermodynamic Data for Inorganic Sulphides, Selenides, and Tellurides", published in 1974, and the series "The Chemical Thermodynamics of Actinide Elements and Compounds", published in parts by the International Atomic Energy Agency since 1976. 
In utilizing data from these various compilations, the user must be aware of certain risks inherent in such use. Many of these have taken data from several different sources and thus the element of self-consistency may be lost. Different standard states for some of the elements may have been used, and the recent change to the standard pressure of 1 bar, while not affecting enthalpy values, may affect entropy and Gibbs energy calculations for reactions involving gases. Thus there are certain advantages that accrue to using such bases that have been developed from original literature sources, such as JANAF, NBS Tables, or the Russian compilations by Gurvich or Medvedev.

And what of the future of data banks? It is clear that they are no longer the task for one or two individuals. Most of the recent compilations mentioned in this report have been the product of groups of workers dedicated to the task of creating these products, usually with some sort of institutional support, both financial and physical. Furthermore most of recent developments in this field have been to make the outputs available in a form suitable for use by computer rather than in printed format. But the activity of data retrieval and evaluation is continuing. The group at the Institute for High Temperatures in Moscow is continuing its intensive effort to publish additional volumes in the series Thermodynamic Properties of Individual Substances, and also maintains a large data base which may be interrogated by computer for thermodynamic functions, equilibrium calculations, etc., under the name IVTAN. At the Vernadsky Institute of Geochemistry in Moscow there exists a system called DIANIK for the solution of thermodynamic problems, solution equilibria, etc., related to geochemistry, and containing data on more than 800 substances. The Design Institute for Physical Properties Data (DIPPR) of the American Institute of Chemical Engineering has been publishing since 1980 a series of loose-leaf tables "Physical and Thermodynamic Properties of Pure Chemicals", edited by Daubert and Danner. These tables cover properties of over 900 industrially important compounds, including estimated values when necessary. Another ongoing project is the Thermodynamics Research Center at Texas A. and M. University previously mentioned. A relatively new data center for data on organic compounds is located here in Moscow at Giprokauchuk but I know very little about it at the present time. There are also such systems as THERM/EST, the NIST (formerly NBS) Standard Reference Data Base for Organic Compounds at $298 \mathrm{~K}$, which can provide either experimental or estimated values of thermodynamic properties for a number of hydrocarbon classes.

And so in concluding this review of the last 110 years of data collection and evaluation it seems to me that the ability and interest to maintain updated thermodynamic information on certain classes of compounds certainly exists as of now. Whether it will survive the constraints caused by economic conditions I do not know. Certainly also the methods to update such major compilations as NBS 270 or the Medvedev tables exist; it can be done by treating large blocks of data systematically. But to do it under CODATA will require a major increase in the effort devoted to that work. 


\section{BIBLIOGRAPHY}

Thermochemische Untersuchungen, Vol. 1 - 4; J. Thomsen; J. A. Barth, Leipzig (1882 - 87).

Thermochimie. Donnees et Lois Numerique, Vol. 1 - 2; M. Berthelot; Gauthiers-Villars and Sons, Paris (1897).

Thermodynamics and the Free Energy of Chemical Substances; G. N. Lewis and M. Randall; McGraw-Hill Book Co., New York (1923).

Oxidation States of the Elements and their Potentials in Aqueous Solution; W. M. Latimer; Prentice-Hall, New York (1938, 1952).

International Critical Tables of Numerical Data, Physics, Chemistry and Technology,Vol. I - VII; E. W. Washburn, Editor-in-Chief; McGraw-Hill Book Co., New York (1926 - 1930).

Thermochemistry of the Chemical Substances; F. R. Bichowsky and F. D. Rossini; Reinhold Publishing Co., New York (1936).

Contributions to the Data of Theoretical Metallurgy, Vol. I - XVI; K. K. Kelley et al.; U. S. Bureau of Mines, (1932 -1976).

Selected Values of Properties of Hydrocarbons, NBS Circular 461; F. D. Rossini, K. S. Pitzer, W. J. Taylor, J. P. Ebert, J. E. Kilpatrick, C. W. Beckett, M. G. Williams, and H. G. Werner; U.

S. Government Printing Office, Washington, D.C. (1947).

Selected Values of Physical and Thermodynamic Properties of Hydrocarbons and Related Compounds; F. D. Rossini, K S. Pitzer, R. L. Arnett, R. M. Braun, and G. C. Pimentel; Carnegie Press, Pittsburgh, Pa. (1953).

Selected Values of Chemical Thermodynamic Properties, NBS Circular 500; F. D. Rossini, D. D. Wagman, W. H. Evans, S. Levine, and I. Jaffe; U. S. Government Printing Office, Washington, D. C. (1952).

Chemistry and Metallurgy of Miscellaneous Materials. Thermodynamics; L. L. Quill, Editor; McGraw-Hill Book Co., New York (1950).

Thermodynamic Properties of the Elements; D. R. Stull and G. C. Sinke; Advances in Chemistry No. 18, American Chemical Society, Washington, D. C. (1956).

Selected Values of Thermodynamic Properties of Metals and Alloys; R. Hultgren, R. L. Orr, P. D. Anderson, and K. K. Kelley; J. Wiley and Sons, New York (1963).

Selected Values of the Thermodynamic Properties of the Elements; R. Hultgren, P. D. Desai, D. T. Hawkins, M. Gleiser, K. K. Kelley, and D. D. Wagman; American Society for Metals, Metals Park, Ohio (1973).

Chemical Thermodynamics of Organic Compounds; D. R. Stull, E. F. Westrum, Jr., and G. C. Sinke; J. Wiley and Sons, New York (1969).

Thermochemistry of Organic and Organometallic Compounds; J. D. Cox and G. Pilcher; Academic Press, London (1970).

Thermochemical Data of Organic Compounds (Second Edition);J. B. Pedley, R. D. Naylor, and S. P. Kirby; Chapman and Hall, London (1986).

JANAF Thermochemical Tables; D. R. Stull, Editor; NTIS, U. S. Department of Commerce, Washington, D. C. (1965).

JANAF Thermochemical Tables (Second Edition); D. R. Stull and H. Prophet, Editors; NSRDS-NBS 37, U. S. Government Printing Office, Washing- ton, D. C. (1971).

JANAF Thermochemical Tables (Third Edition); M. W. Chase, Jr.,C. A. Davies, J. R. Downey, Jr., D. J. Frurip, R. A. McDonald, and A. N. Syverud; J. Phys. Chem. Ref. Data 14, Supplement 1 (1985).

Thermodynamic Properties of the Components of Combustion Products; L. V. Gurvich et al.; Academy of Sciences U. S. S. R., Moscow (1956).

Thermodynamic Properties of Individual Substances; L. V. Gurvich et al.; Academy of Sciences U. S. S. R., Moscow $(1962,1978)$.

Thermodynamic Properties of Individual Substances (Fourth Edition in English, Vol. 1 - 5); L. V. Gurvich, I. Veyts, and C. B. Alcock, Editors; Hemisphere Publishing Corp., New York (1990).

Selected Values of Chemical Thermodynamic Properties; NBS Technical Note 270 (Parts 1 - 8); D. D. Wagman et al; U. S. Government Printing Office, Washington, D. C. (1965 - 81); J. Phys. Chem. Ref. Data 11, Supplement 1 (1982).

Thermal Constants of Substances; V. A. Medvedev et al.; Academy of Sciences U. S. S. R., Moscow (1965 - 81).

CODATA Key Values for Thermodynamics; J. D. Cox, D. D. Wagman, and V. A. Medvedev; Hemisphere Publishing Corp., New York (1989). 
CODATA Thermodynamic Tables: Selections for Some Compounds of Calcium and Related Mixtures: A Prototype Set of Tables; D. Garvin, V. B. Parker, and H. J. White, Jr., Editors; Hemisphere Publishing Corp., New York (987).

Thermochemical Properties of Inorganic Substances; I. Barin and O. Knacke; Springer Verlag, Berlin (1973).

Thermochemical Data of Pure Substances; I. Barin; VCH Verlags gmbH, Weinheim, Germany (1989).

Thermodynamic Data for Inorganic Sulphides, Selenides and Tellurides; K. C. Mills; Butterworths and Co., London (1974).

Chemical Thermodynamics of Actinide Elements and Compounds; F. L. Oetting, V. A. Medvedev, M. H. Rand, and E. F. Westrum, Jr., Editors: International Atomic Energy Agency, Vienna, Austria (1976 - 85). 